\title{
THE INTEGRATED LAW SCHOOL CURRICULUM
}

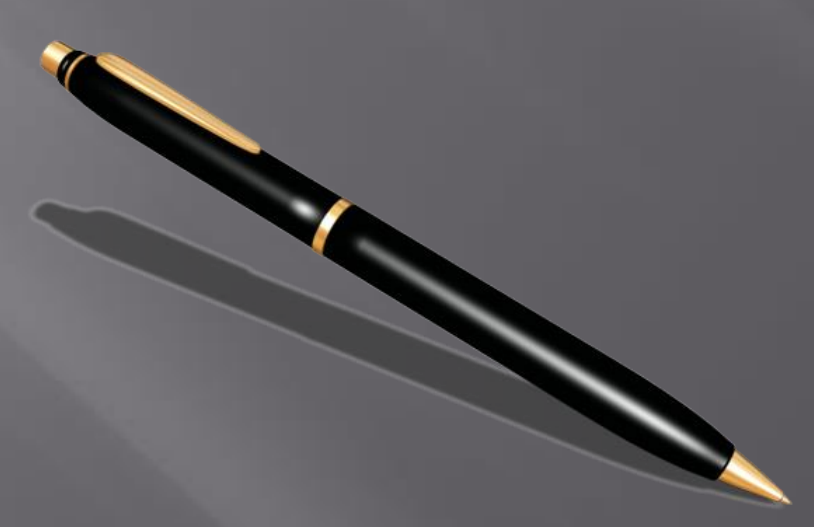




\section{Summary}

口 Developing a Fully-Integrated Curriculum

- Competency-Based Learning Outcomes

- Formative and Summative Assessments Tied To Achievement of Learning Outcomes

- Collapsing the Distinction Between Doctrinal, Skills, and Clinical Courses

口 Three Components

- The Cross-Curricular Model

- A Thirteen-Credit, Six-Semester Legal Writing Program

- Incorporating Experiential Learning into Doctrinal Courses 


\section{The Cross-Curricular Model}

First Semester of $1 L$ Year

$\square$ Students Receive a Multi-Issue "Umbrella" Hypothetical Containing Legal Issues from All First-Year Courses.

$\sqsupset$ Vertical Integration: Students Draft Litigation Documents As They Acquire Substantive Law

- Contracts: Students Study Contract Formation Principles and Draft a Retention Agreement

- Civil Procedure: Students Study Pleading Rules Before Drafting a Complaint

$\sqsupset$ Horizontal Integration: Students Litigate a Case from Client Interview to Appellate Brief in the First Three Semesters 


\section{Upper-Level Cross-Curricular Hypotheticals}

$\sqsupset 2 \mathrm{~L}$ Year

$\sqsupset$ (Fall): Students Complete a Litigation-Based Cross-Curricular Hypothetical

$\sqsupset$ (Spring): Students Complete a Transactional Law-Based CrossCurricular Hypothetical 
Upper-Level Cross-Currícular Hypotheticals (cont.)

$\sqsupset 3 \mathrm{~L}$ Year - Students Complete a Criminal Trial-Based Cross-Curricular Hypothetical

$\sqsupset$ All Assignments in Cross-Curricular Hypothetical Are Graded With Detailed Rubrics by Doctrinal and Legal Writing Faculty

$\sqsupset$ Students Receive Detailed Feedback

$\sqsupset$ Rewriting Assignments Are Incorporated 


\section{Assignment Sequencing}

Order of Assignments

$\sqsupset$ First Semester of 1L Year

- Client Meeting (Criminal Law)

- First Research Assignment (Legal

Research)

- Predictive Memorandum (Legal

Writing)

- Client Letter (Legal Writing)

- Complaint (Civil Procedure)

- Presentation to Partner (Legal

Writing) 
Assignment Sequencing (cont.)

$\sqsupset$ Second Semester of 1L Year

- The Motion to Dismiss (Legal

Writing II)

- The Answer (Property)

- Discovery (Torts)

- Motion to Compel (Foundations of Legal Analysis II)

- The Motion for Summary Judgment (Legal Writing II) with Oral Argument 


\section{Assignment Sequencing (cont.)}

$\square \underline{\text { The Third Semester }}$

- Fictional Opinion By District Court (Federal Judicial Intern Practicum)

- The Appellate Brief and Oral Argument (Legal Writing III) 


\section{Assignment Sequencing (cont.)}

口 2L Litigation-Based Cross-Curricular Hypothetical (fall)

- Predictive Memorandum (Professional Responsibility)

- Motion in Opposition to Summary Judgment (Constitutional Law)

- Re-write of Motion in Opposition to Summary Judgment (Legal Writing III)

ㅁ 2L Transactional-Law Based CrossCurricular Hypothetical (spring)

- Partnership Agreement (Business Organizations)

- Last Will and Testament (Wills, Trusts, \& Estates)

- Security Agreement (Commercial Law) 


\section{Assignment Sequencing (cont.)}

口 3L Criminal Law-Based CrossCurricular Hypothetical

- Predictive Memorandum(4th Amendment Issue)

- Motion to Suppress Evidence (Criminal Procedure)

- Re-write of Motion to Suppress Evidence (Legal Writing V) 


\section{SIX SEMESTERS OF REQUIRED EXPERIENTIAL LEGAL WRITING}




\section{Required Legal Writing Credits}

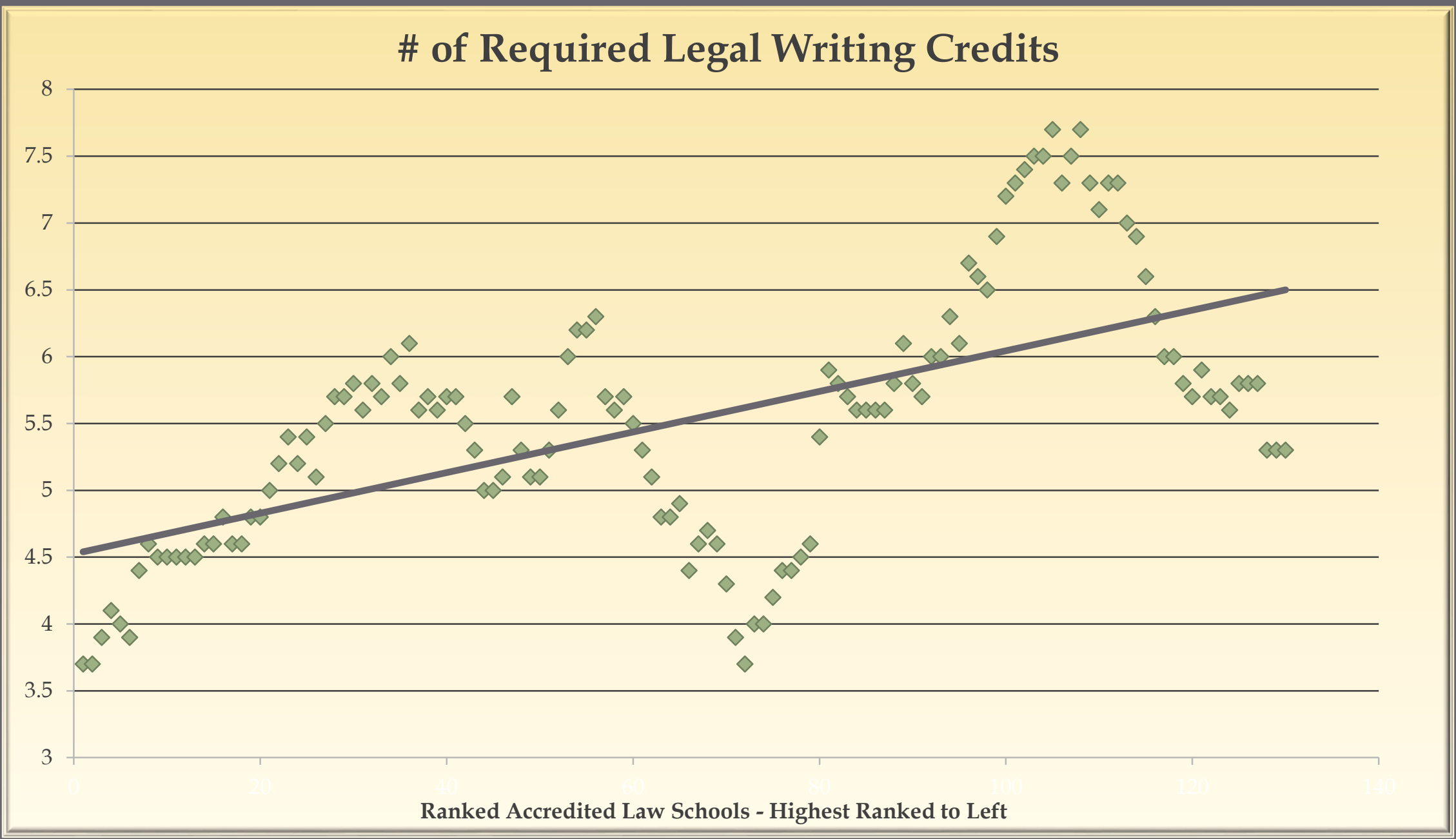




\section{Writing Throughout the Curriculum}

口 Legal Writing I (Predictive Writing)

口 Legal Writing II (Persuasive Writing)

口 Legal Writing III (Appellate Brief Writing)

口 Legal Writing IV (Transactional Drafting)

口 Legal Writing V (Rewriting and Editing)

口 Legal Writing VI (Narrative Storytelling) 


\section{Writing Throughout the Curriculum (cont.)}

$\sqsupset$ Experiential Legal Writing I and II

- A Second, Multi-Issue "Umbrella" Hypothetical that Complements the 1L Cross-Curricular Hypothetical

$\sqsupset$ Experiential Legal Writing III through VI

- Targeted Fact Patterns With Simulations Incorporated

- Emphasis on Re-Writing and Narrative Storytelling 


\section{Benefits of an Integrated Curriculum}

$\sqsupset$ Outcomes: Students Acquire Real-World Lawyering Competencies (ABA Standard 314 and 315)

$\square$ Skills: The Curriculum Focuses on Skills Many Graduates Lack - Legal Writing, Persuasive Advocacy, Professional and 'Soft' Skills

$\sqsupset$ Assessment: Faculty Use Formative and Summative Assessments to Monitor and Evaluate Students' Performance 